\title{
The Challenges of a Dopamine Secreting Paraganglioma
}

\section{Lewis AS ${ }^{1}$, Harper R², Hunter SJ1, Mullan K1}

\section{${ }^{1}$ Regional Centre for Diabetes and Endocrinology, Royal Victoria Hospital, Belfast, ${ }^{2}$ Ulster Hospital, Dundonald, Belfast}

\section{HISTORY}

- 39 year old female

- 18 month history of borderline hypertension, headaches, palpitations and some anxiety symptoms

- Family history of hypertension in both parents

\section{EXAMINATION}

- BP $160 / 102$

- No medications

- Large single cafe au lait spot

- No neurofibromata

- Remaining examination unremarkable

\section{URINARY CATECHOLAMINES}

\begin{tabular}{|l|c|c|c|c|}
\hline & $\begin{array}{c}\text { Volume } \\
(\mathrm{mls})\end{array}$ & $\begin{array}{c}\text { Dopamine } \\
(\mathrm{nmol} / \mathbf{2 4 h})\end{array}$ & $\begin{array}{c}\text { Noradrenaline } \\
(\mathrm{nmol} / \mathbf{2 4 h})\end{array}$ & $\begin{array}{c}\text { Adrenaline } \\
(\mathrm{nmol} / \mathbf{2 4 h})\end{array}$ \\
\hline Normal & & $300-3900$ & $50-560$ & $5-120$ \\
\hline $10 / 12 / 2009$ & 2300 & $\mathbf{8 2 7 3}$ & 265 & 35 \\
\hline $24 / 12 / 2009$ & 2600 & 6934 & 367 & 23 \\
\hline $05 / 05 / 2010$ & 2200 & $\mathbf{8 6 5 3}$ & 240 & 26 \\
\hline $06 / 05 / 2010$ & 2600 & 5398 & 120 & 16 \\
\hline
\end{tabular}

\section{IMAGING}

Meta-iodobenzylguanidine (MIBG I-123) scanning indicated a single focus of activity further defined on SPECT-CT as a 12 $\mathrm{mm}$ mass in the lower paraaortic region

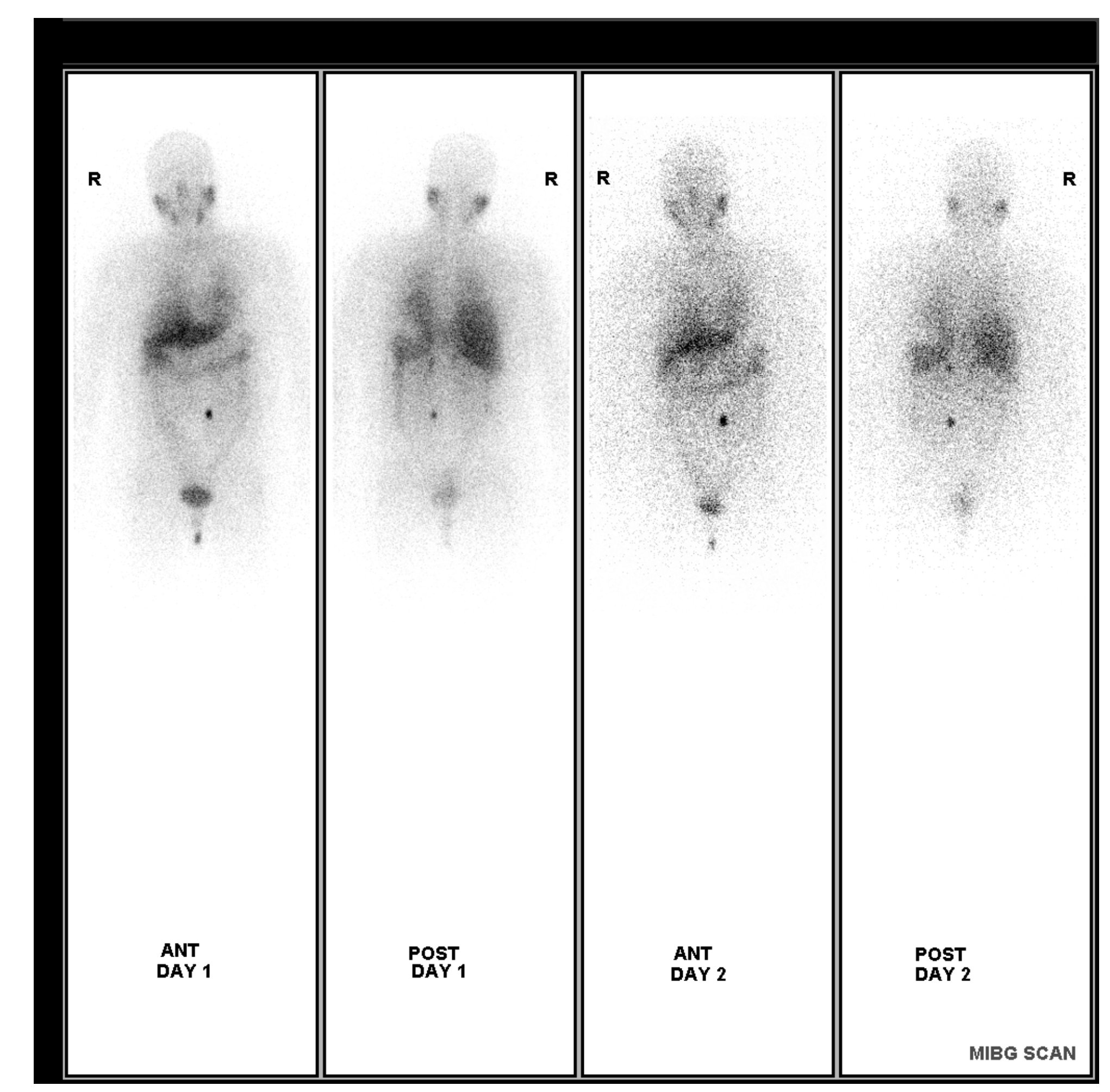

Fig 1. MIBG scan showing lower left para-aortic focus

\section{FURTHER INVESTIGATIONS}

- Calcium 2.83mmol/L

$(\mathrm{N}=2.2-2.6)$

- $\mathrm{PTH} 274 \mathrm{pg} / \mathrm{ml}$

$(\mathrm{N}=15-70)$

- Calcitonin $<5.0 n g / L$

- Nuclear uptake scan indicated a right lower parathyroid focus

\section{MANAGEMENT}

- BP controlled with amlodipine and lisinopril prior to surgery

- After a 30 second asystolic episode during first manipulation of the tumour a black lobulated paraganglioma was removed at the organ of Zuckerkandl

- Urinary dopamine normalised post-operatively (2147nmol/24h) and blood pressure settled

- Right lower parathyroid adenoma was removed uneventfully 5 months later and calcium normalised $(2.52 \mathrm{mmol} / \mathrm{L})$

- Antihypertensives have now been fully withdrawn

- Genetic testing to date has been negative including MEN2a, succinate dehydrogenase $\mathrm{B}, \mathrm{C}$ and $\mathrm{D}$ mutations

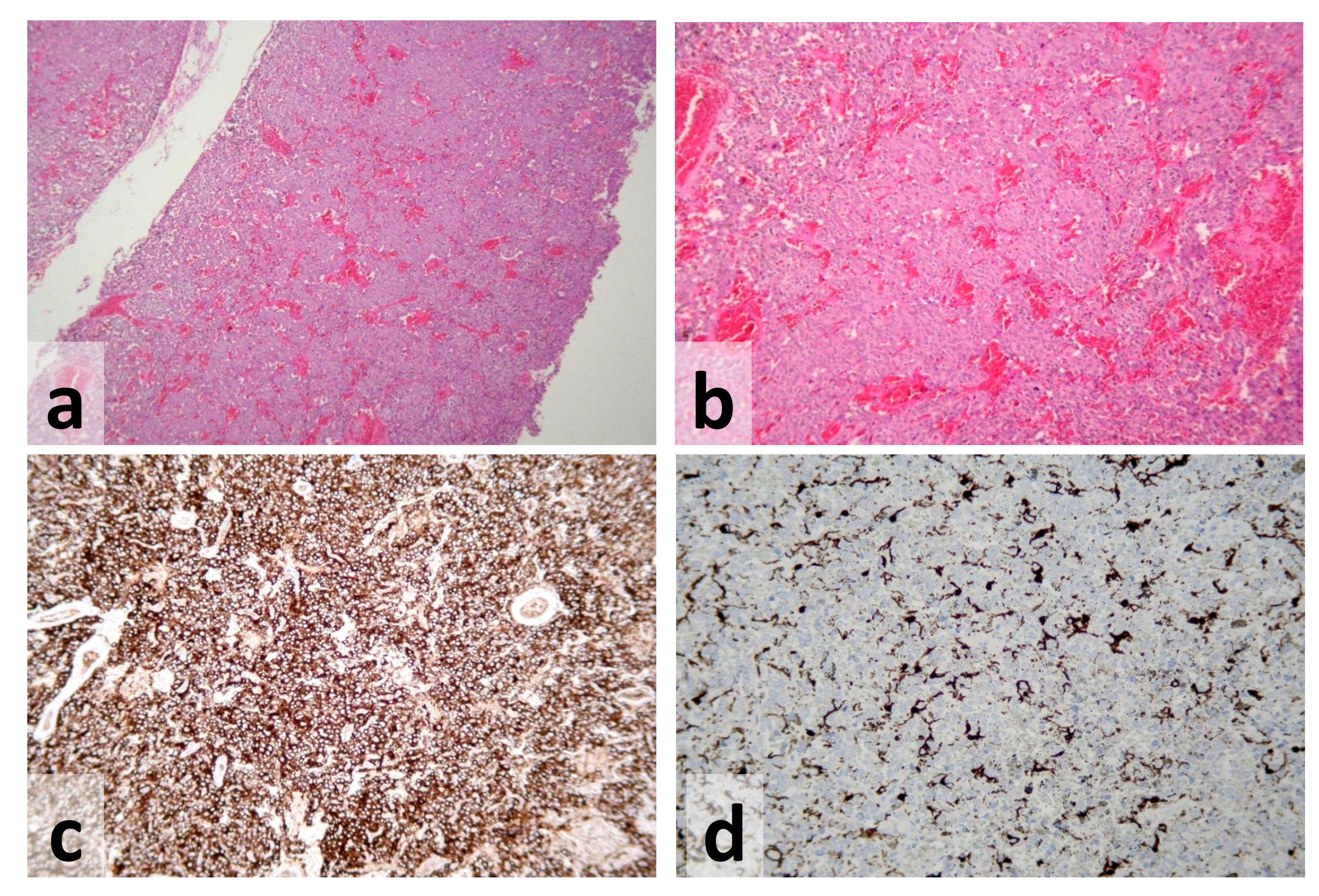

Fig 3. Histology from this patient's paraganglioma (a) and (b) H\&E stain; (c) chromogranin A staining diffusely positive; (d) $S 100$ stains the sustentacular cells

\section{USUAL CAUSES OF RAISED URINARY DOPAMINE LEVELS}

- Over- collection

- Tricyclic Antidepressants

- Levodopa

- Drugs containing adrenergic receptor agonists (eg decongestants)

- Amphetamines
- Buspirone and most psychoactive agents

- Prochlorperazine

- Reserpine

- Withdrawal from clonidine and other drugs

- Ethanol

\section{DISCUSSION}

- Dopamine secreting paragangliomas are extremely rare and are usually metastatic at diagnosis

- They are usually associated with nonspecific symptoms, normotension and present with mass effects

- Alpha blockade is contraindicated because of its association with cardiovascular collapse which is due to the unopposed hypotensive action of dopamine when the pressor catecholamines are blocked

- They are less likely to enhance with MIBG scanning

- Lifelong surveillance is recommended given high recurrence and malignancy rates

- To our knowledge this is the first reported case of a dopamine secreting paraganglioma presenting with a coexistent parathyroid adenoma 